\title{
COMPUTATIONAL THINKING DALAM PEMBELAJARAN MATEMATIKA MENGHADAPI ERA SOCIETY 5.0
}

\author{
Anggita Maharani \\ Universitas Swadaya Gunung Djati, Jl. Perjuangan, Cirebon; anggi3007@yahoo.co.id
}

\begin{abstract}
This article discusses the ability of Computational Thinking as an essential ability Era Society 5.0, where digitization of artificial intelligence, robotics, automation, big data, cyber has become part of the activities of human life while changing the human-centered order to technology-based. Computational thinking includes specific thinking abilities, problemsolving abilities including abstraction, decomposition, evaluation, patterns, recognition, logic, and algorithm design. The article was compiled based on the study of more than 50 kinds of literature in various fields of science, especially informatics and its relation to mathematics obtained through the national scientific data bureau, DOAJ, and Google Scholar. Literature sources are examined qualitatively through the stages of text interpretation, coding, analysis, discussion, and reconsideration. The discussion description refers to the context of Computational Thinking, measurement indicators, methods of development, and their implementation in learning Mathematics. To develop computational thinking, we need dispositions related to complexity and persistence in working with difficult problems, the ability to ambiguity, the ability to deal with open-ended problems, and the ability to communicate. Implementation of TPACK (technological pedagogical technologic content knowledge) in developing computational thinking needs to examine more deeply about strategies and problem-solving methods that can link computational thinking with teaching practices.
\end{abstract}

Keywords: Computational thinking, Mathematics, Society 5.0, Artificial intelligence.

\section{Pendahuluan}

Perjalanan zaman dalam kehidupan manusia sudah barang tentu menjadi sudah keniscayan. Di era revolusi industri 4.0 manusia dimungkinkan untuk dapat mengakses sekaligus membagikan informasi via internet. Memasuki era 5.0 semua teknologi sudah menjadi bagian dari manusia itu sendiri (Al Faruqi, 2019; Ferreira \& Serpa, 2018; Salgues, 2018). Hal inilah yang membuat era 5.0 disebut sebagai era Society atau di Indonesia disebut era revolusi sosial atau era peradaban.

Era Society 5.0 lahir di Jepang dan telah diresmikan pada tanggal 21 Januari 2019 sebagai persiapan memasuki tahun 2025 (Innovation 25) dimana

Euclid, p-ISSN 2355-1712, e-ISSN 2541-4453, Vol. 7, No. 2, pp. 77- 147 CLembaga Penelitian Universitas Swadaya Gunung Jati (UGJ), Cirebon. 
industri membutuhkan masyarakat yang super pintar (Fujii, Guo, \& Kamoshida, 2018; Fukuda, 2019; Fukuyama, 2018; Gladden, 2019; Shiroishi, Uchiyama, \& Suzuki, 2018). Seperti yang telah banyak dibahas, bahwa pada era revolusi 1.0 manusia baru mengenal tulisan. Mereka bertahan hidup dengan cara memanfaatkan tumbuhan alami dan berburu. Memasuki zaman revolusi industri 2.0 (awal abad 19) manusia sudah mulai mengenal teknologi dan bercocok tanam. Sektor pertanian mulai berkembang ke arah produksi makanan. Sedangkan di zaman revolusi industri 3.0 untuk pertamakalinya manusia memasuki era industri. Dilahirkan di Inggris, memasuki era revolusi industri 3.0 tenaga manusia mulai tergantikan oleh mesin. Pada zaman ini teknologi dan kegiatan manufacture mulai dikembangkan guna membantu aktivitas manusia hingga kemudian lahir zaman Society 4.0 dimana manusia sudah mengenal internet dan mahir memanfaatkannya. Memasuki Society 5.0 internet bukan lagi dimanfaatkan oleh manusia, namun manusialah yang kini bergantung pada internet (Dey, Roy, \& Das, 2016; Heliany, 2019; Khosla, Damiani, \& Grosky, 2003). Internet seakan menjadi kebutuhan primer manusia.

Revolusi 5.0 bukan sekedar transformasi. Teknologi dalam sendi-sendi kehidupan manusia merambah pada setiap sektor. Digitalisasi artificial intelegence, robotik, otomasi, big data, cyber, telah menjadi bagian dari aktifitas kehidupan manusia sekaligus merubah tatanan human-centered ke technology-based (Al Faruqi, 2019; Mumtaha \& Khoiri, 2019). Istilah Internet of Things (IoT) kemudian berkembang tidak hanya di kota-kota besar tapi sampai ke pelosok negeri.

Internet of Things (IoT) semacam gagasan menanamkan sistem jaringan ke dalam kehidupan kita, yakni jaringan data seperti pada smartphone dan tablet (Tanwar, Patel, Patel, Tyagi, Kumar, \& Obaida 2017; Zhang \& Green, 2015). Pemilik smartphone dengan mudah memiliki akses dalam bentuk kamera untuk berkomunikasi bahkan bertatap muka dengan manusia lain yang jaraknya sangat jauh. Mereka juga dapat memperoleh pengetahuan dari luar melalui bacaan ataupun tontonan informasi bahkan tontonan langsung mengenai kegiatan yang sedang berlangsung meskipun lokasinya sangat jauh. Internet of Things (IoT) telah menyediakan platform yang memungkinkan perangkat terhubung, merasakan, dan mengontrol jarak jauh melalui infrasutruktur jaringan. Sistem jaringan yang dirancang dapat bersifat ekonomis karena adanya peluang koneksi dan pengendalian sejumlah perangkat yang berbeda. Internet of Things (IoT) memiliki prosesor pintar yang menangkap sensor suhu, asap, gerak, visual, kelembaban, dll sebagai input data untuk diteruskan pada alat penggerak (Sediyono, 2019).

Euclid, p-ISSN 2355-1712, e-ISSN 2541-4453, Vol. 7, No. 2, pp. 77- 147

CLembaga Penelitian Universitas Swadaya Gunung Jati (UGJ), Cirebon. 
Fitur-fitur yang terkoneksi internet dapat dikontrol menggunakan perangkat seluler dan komputer jarak jauh (Dey, Roy, \& Das 2016; Lee \& Lee, 2016).

Artificial intelegence (AI) pada era Society 5.0 mengolah big data untuk memfasilitasi berbagai kebutuhan manusia. Implementasinya kini telah ada di berbagai sektor (Nilsson, 2014; Pangkey, Furkan, \& Herman, 2019; Tjandrawinata, 2016). Sebut saja pelayanan rumah pintar seperti adanya CCTV, robot pembersih rumah dan mesin pintar sebagai pelayan. Pelayanan keamanan melalui optimalisasi fungsi satelit dan robot-robot canggih sperti drone memungkinkan kita mendapatkan informasi pada suatu lokasi tanpa harus mengirim orang ke lokasi tersebut. Belum lagi bermunculannya alat transportasi yang juga serupa robot. Di bidang otomotif, mobil era Society 5.0 diprogram untuk dapat parkir sendiri, pintunya terbuka sendiri hanya dengan mendekatkan tubuh, sampai dengan sensor gerak yang ada di sekelilingnya sehingga meminimalisir tingkat kecelakaan.

Berdasarkan uraian tersebut, kajian ini bertujuan untuk membahas kemampuan Computational Thinking dalam pembelajaran matematika sebagai kemampuan esensial Era Society 5.0.

\section{Metode Penelitian}

Kajian dilakukan berdasarkan lebih dari 50 literatur berbahasa Inggris dari berbagai bidang ilmu khususnya informatika serta kaitannya terhadap matematika dan pembelajaran matematika. Literatur diperoleh melalui basis data ilmiah nasional, DOAJ, dan Google Schoolar. Penelusuran sumber informasi dimulai dari artikel hasil publikasi Jeannete Wing pada sebuah conference untuk pertamakalinya di Tahun 2006 hingga ditemukannya istilah computational thinking oleh Seymour Papert pada tahun 1969. Hasil penelusuran literatur kemudian lebih banyak ditemukan pada jurnal Internasional khususnya pada bidang informatika dan matematika. Pencarian tidak dibatasi oleh kriteria jurnal penerbit namun berdasarkan tren publikasi yang mencakup semua artikel tentang computational thinking. Kata kunci yang digunakan adalah computational thinking dan istilah digitalisasi yang sesuai dengan trend Society 5.0 sperti artificial intelegence, robotik, otomasi, big data, cyber. Selain jurnal Internasional, sumber literatur utama lain yang digunakan juga dalam bentuk buku. Seluruh sumber informasi berasal dari literatur berbahasa Inggris baik dalam bentuk jurnal ilmiah ataupun buku yang dapat dibaca ataupun diakses secara online.

Sumber literatur dikaji secara kualitatif melalui tahap intepretasi teks, penyusunan kode, analisis, diskusi, dan pertimbangan kembali (Hart, Smith, Swars, \& Smith, 2009). Intepretasi teks dikaji mulai dari judul, abstrak, dan kata kunci. Pencarian

Euclid, p-ISSN 2355-1712, e-ISSN 2541-4453, Vol. 7, No. 2, pp. 77- 147 CLembaga Penelitian Universitas Swadaya Gunung Jati (UGJ), Cirebon. 
dan penggunaan kata kunci yang sesuai, memudahkan tahap ini. Selanjutya penyusunan berdasarkan tinjauan literatur dan penelitian empiris. Dari seluruh literatur, computational thinking saat ini lebih banyak dibahas berdasarkan tinjauan literatur meskipun computational thinking lahir berdasarkan riset mengenai aktivitas mental. Meskipun demikian, terdapat beberapa artikel yang membahas mengenai temuan hasil riset computational thinking khususnya pada pembelajaran matematika. Kajian literatur dan data empiris yang ditemukan kemudian dianalisis untuk mencapai definisi, indikator pengukurannya, dan bagaimana implementasinya dalam pembelajaran matematika di kelas. Hasil diskusi melahirkan pembahasan yang merujuk pada konteks Computational Thinking, bagaimana cara mengukurnya? Bagaimana mengembangkannya? Bagaimana implementasinya dalam pembelajaran Matematika?

Kajian tentang TPACK (technological pedagogical technologic content knowledge) dan STEM (Science Technology Education and Mathematics) akhirnya dikaitkan sebagai suatu strategi dan pendekatan yang dapat digunakan untuk mengembangkan computational thinking dalam raktik mengajar.

Intepretasi, analisis, dan pengkajian kembali suatu data sangat dipengaruhi oleh kemampuan dan pengalaman penulis. Untuk selanjutnya, hasil diskusi dapat diulas lebih lanjut.

\section{Hasil dan Pembahasan}

Penelusuran literatur melibatkan lebih dari 50 sumber bacaan yang terdiri dari jurnal ilmiah maupun buku yang seluruhnya berbahasa Inggris. Di Indonesia, saat ini masih belum ditemukan literatur yang membahas computational thinking terutama bila dikaitkan dengan matematika dan pembelajaran matematika.

\subsection{Computational Thinking}

Artificial intelegence (AI) melibatkan logika, probalilitas, matematika lanjut, penalaran, pembelajaran, dan tindakan yang menggunakan mikroelektronik untuk pemecahan masalah yang rumit (Charniak, 1985; Genesereth \& Nilsson, 2012; Luger, 2005; Russell \& Norvig, 2016). Komputer telah merubah tatanan kehidupan manusia di berbagai sektor dan secara terintegrasi memacu inovasi dalam berpikir dan bertindak. Atas dasar itulah, kemampuan komputasi (computational thinking) kini menjadi kemampuan yang sangat esensial. Keterampilan komputasi bukan hanya harus dimiliki oleh ilmuwan komputer, namun oleh semua orang (J. M. Wing, 2006, 2008). Berbagai aktivitas yang melibatkan STEM (science, technology, education, and mathematics) sangat diperlukan sebagai sarana memecahkan masalah secara kreatif dan inovatif pada setiap bidang ilmu.

Euclid, p-ISSN 2355-1712, e-ISSN 2541-4453, Vol. 7, No. 2, pp. 77- 147

CLembaga Penelitian Universitas Swadaya Gunung Jati (UGJ), Cirebon. 
Computational thinking dikenalkan oleh Seymour Papert pada tahun 1969 (Catlin \& Woollard, 2014) melalui pengembangan program robot turtle. Risetnya mengenai aktivitas mental melalui program komputer sebagai hasil dari konstruksi pemikiran manusia. Istilah computational thinking ini kemudian dipopulerkan oleh Jeannete Wing melalui pembahasan mengenai perspektif tentang hubungan teori pengunaan praktis dari robot turtle. Menurut Jeannete Wing, computational thinking merupakan cara berpikir yang melibatkan pemrosesan informasi termasuk pemikiran algoritmik, penalaran, pola, pemikiran prosedural dan pemikiran rekursif (Wing, 2011). Grover and Pea mendeskripsikan computational thinking sebagai kompetensi yang mendukung kegiatan analisis. Computational thinking meliputi kemampuan berpikir spesifik, kemampuan pemecahan masalah termasuk abstraksi, dekomposisi, evaluasi, pola, recognition, logika, dan desain algoritma (Grover \& Pea, 2018). Berikut ini adalah indikator computational thinking menurut Selby \& Woollard (Catlin \& Woollard, 2014)

Tabel 1. Konsep dan Kompetensi Computational Thinking

\begin{tabular}{|c|c|}
\hline Konsep & Kompetensi \\
\hline Abstraksi & $\begin{array}{l}\text { Berkaitan dengan kompleksitas melalui reduksi unsur } \\
\text { yang tidak perlu }\end{array}$ \\
\hline Algoritma & Mengidentifikasi urutan \\
\hline Decomposition & $\begin{array}{l}\text { Memecahkan artefak, proses, atau sistem menjadi } \\
\text { suatu komponen }\end{array}$ \\
\hline Generalisasi & $\begin{array}{l}\text { Mengidentifikasi pola dan kesamaan antara artefak, } \\
\text { proses atau sistem }\end{array}$ \\
\hline Analisis Logika & Menerapkan dan menafsirkan logika Boolean \\
\hline Evaluasi & $\begin{array}{l}\text { Sistematika menghasilkan nilai yang dapat dibuktikan } \\
\text { penilaiannya }\end{array}$ \\
\hline
\end{tabular}

Memasuki abad ke-21 computational thinking menjadi keterampilan dasar yang wajib dimiliki oleh seluruh siswa seperti halnya kemampuan membaca, menulis, dan berhitung (Román-González, Pérez-González, \& JiménezFernández, 2017; Tabesh, 2017; J. M. Wing, 2014). Cara-cara pembelajaran yang melibatkan computational thinking dapat dilakukan melalui cerita, permainan, simulasi interaktif. Siswa dilibatkan dalam kegiatan pemrograman mulai dari menyusun konsep, membuat desain, dan praktik. Penilaian computational thinking (Brennan \& Resnick, 2012) dapat dilakukan melalui pendekatan pengembangan analisis portofolio, wawancara berbasis artefak, dan skenario desain. Instrumen computational thinking yang telah dikembangkan (Román-González, Pérez-González, \& Jiménez-Fernández, 
2017) menggunakan standar psikologi soal tes pemecahan masalah yang berhubungan dengan kemampuan spasial, penalaran, dan kemampuan pemecahan masalah.

Tahun 2009 proyek ISTE dan Computer Science Teacher Association (CSTA) telah merumuskan konsep computational thinking yang dapat diakses oleh para pendidik di semua tingkatan kelas dan semua disiplin ilmu (Barr, Harrison, \& Conery, 2011). Rumusan yang dihasilkan adalah computational thinking sebagai (a) proses penyelesaian masalah yang melibatkan perumusan masalah baik menggunakan komputer atau alat bantu lainnya; (b) pengelolaan data analisa logis; (c) representasi data melalui abstraksi seperti model dan simulasi; (d) otomasi solusi melalui pemikiran algorithmic; (e) identifikasi, analisis, dan implementasi solusi; (f) melakukan generalisasi. Beberapa dimensi penting yang perlu dimiliki untuk mendukung computational thinking diantaranya disposisi yang berkaitan dengan kompleksitas, kegigihan dalam bekerja dengan masalah yang sulit, toleransi terhadap ambiguitas, kemampuan terkait masalah open-ended, dan kemampuan berkomunikasi.

Mengembangkan computational thinking sebagai jawaban dari tantangan zaman, tentu memberi dampak khususnya bagi guru matematika mengingat computational thinking erat kaitannya dengan matematika (Gadanidis, 2017; Liu \& Wang, 2010; Orton, Weintrop, Beheshti, Horn, Jona, \& Wilensky, 2016; Sung, Ahn, \& Black, 2017; Sysło \& Kwiatkowska, 2014; Weintrop, Beheshti, Horn, Orton, Jona, Trouille, Wilensky, 2016). Untuk anak usia dini (4- 7 tahun), membangun computational thinking dapat dilakukan dengan menggunakan balok kayu. Pemrograman sederhana dilakukan anak-anak melalui integrasi seni (Bers, 2008). Sedangkan untuk siswa K-12 pengembangan computational thinking sangat memerlukan kolaburasi pendidikan ilmu komputer (Barr \& Stephenson, 2011; Sengupta, Kinnebrew, Basu, Biswas, \& Clark, 2013; Yadav, Zhou, Mayfield, Hambrusch, \& Korb, 2011). Computational thinking dan pemrograman terintegrasi di dalam kurikulum STEM K-12.

\subsection{Technological, Pedagogical and Content Knowledge (TPACK) dalam Mengembangkan Computational Thinking}

Seiring dengan kemajuan, guru era Society 5.0 memiliki tantangan mengintegrasikan teknologi secara efektif ke dalam pengajaran di kelas. Meskipun demikian, teknologi tentu tidak dapat menggantikan peran guru sepenuhnya. Pendidikan nerupakan pengalaman sosial yang tidak dapat disimulasikan oleh komputer (Elkind, 1996). Melibatkan teknologi dalam

Euclid, p-ISSN 2355-1712, e-ISSN 2541-4453, Vol. 7, No. 2, pp. 77- 147

CLembaga Penelitian Universitas Swadaya Gunung Jati (UGJ), Cirebon. 
pembalajaran bukan hanya sebatas menggunakan komputer. Salah satu unsur yang harus ada dalam pembalajaran adalah unsur pedagogik. Oleh karena itu, penggunaan teknologi dalam pembelajaran memerlukan suatu pemahaman mengenai prinsip pedagogik khususnya dalam mengintegrasikan teknologi. Dalam praktiknya, pemilihan berbagai alat pengajaran dan aplikasi teknologi perlu disertai pemilihan strategi pembelajaran yang dipadukan dengan ilmu pedagogi (Keengwe \& Onchwari, 2009; Yadav, Zhou, Mayfield, Hambrusch, \& Korb, 2011). Pengetahuan dan pemahaman mengenai integrasi teknologi dan pedagogi untuk selanjutnya dikenal dengan istilah TPACK (technological pedagogical content knowledge). Prinsip yang dapat dikembangkan dalam mengintegrasikan teknologi (Blum \& Parette, 2015) diantaranya: (a) teknologi yang harus selaras dengan kurikulum; (b) pemilihan teknologi harus berdasarkan kebutuhan pengajaran; (c) guru harus dapat memastikan peluang seluruh siswa dapat berpartisipasi dan belajar.

Beberapa hasil riset (Sung, Ahn, \& Black, 2017; Voskoglou \& Buckley, 2012; Wang, Kinzie, McGuire, \& Pan, 2010) memberikan indikasi bahwa penggunaan teknologi khususnya komputer sebagai alat untuk pemecahan masalah dalam kelas STEM dapat meningkatkan kemampuan siswa dalam memecahkan masalah dunia nyata dengan melibatkan pemodelan matematika. Siswa dapat mengeksplorasi kemampuannya melalui proses penyelidikan dengan bantuan komputer. Teknologi dalam pembelajaran menjadi penting sebagai upaya memperkaya atau menyediakan konteks masalah, memfasilitasi sumber daya, dan mendukung proses kognitif maupun metakognitif. Untuk mengembangkan computational thinking dalam pembelajaran di kelas diperlukan tahapan: (a) memahami computational thinking; (b) merancang konsep/desain pembelajaran; (c) mengintegrasikan konsep dan ilmu pedagogi. Tantangannya adalah dalam mengkonseptualisasikan dan mengintegrasikan computational thinking dalam konten pedagogi terutama pada tahap desain (Kale, Akcaoglu, Cullen, Goh, Devine, Calvert, \& Grise 2018; Yang, Mouza, \& Pan, 2018). Selain mengembangkan pengetahuan tentang teknologi, konten, dan pedagogi, guru perlu mengenali relevansi computational thinking dengan pengajaran yang mereka lakukan. Implementasi TPACK dalam mengembangkan computational thinking perlu mengkaji lebih dalam mengenai strategi dan metode pemecahan masalah yang dapat menghubungkan computational thinking dengan praktik pengajaran. 


\section{Simpulan}

Hampir seluruh artikel membahas mengenai konsep namun tidak disertai dengan indikator yang mudah terukur. Artikel membahas studi literatur dan studi empiris tentang kemampuan computational thinking. Pembahasannya meliputi definisi, indikator, metode pengembangannya, dan implementasinya di dalam pembelajaran. Uraian lebih bersifat deskriptif. Temuannya adalah dalam praktik pengajaran guru baru sampai pada tataran paham computational thinking namun masih sulit dalam mendesain pembelajaran. Keterlibatan komputer menjadi suatu keharusan dan diperlukan tim multidisiplin baik untuk melakukan pengajaran di kelas maupun riset.

\section{Daftar Pustaka}

Al Faruqi, U. (2019). Future Service in Industry 5.0. Jurnal Sistem Cerdas, 2(1), $67-79$.

Barr, D., Harrison, J., \& Conery, L. (2011). Computational thinking: A digital age skill for everyone. Learning $\mathcal{E}$ Leading with Technology, 38(6), 20-23.

Barr, V., \& Stephenson, C. (2011). Bringing computational thinking to K-12: what is Involved and what is the role of the computer science education community? Acm Inroads, 2(1), 48-54.

Bers, M. U. (2008). Blocks to Robots Learning with Technology in the Early Childhood Classroom. Teachers College Press.

Blum, C., \& Parette, H. P. (2015). Universal design for learning and technology in the early childhood classroom. In Young children and families in the information age (pp. 165-182). Springer.

Brennan, K., \& Resnick, M. (2012). New frameworks for studying and assessing the development of computational thinking. In Proceedings of the 2012 annual meeting of the American educational research association, Vancouver, Canada (Vol. 1, p. 25).

Catlin, D., \& Woollard, J. (2014). Educational robots and computational thinking. In Proceedings of 4 th International workshop teaching robotics, teaching with robotics $\mathcal{E} 5$ th International conference robotics in education (pp. 144-151).

Charniak, E. (1985). Introduction to artificial intelligence. Pearson Education India.

Dey, S., Roy, A., \& Das, S. (2016). Home automation using Internet of Thing. In 2016 IEEE 7th Annual Ubiquitous Computing, Electronics \& Mobile Communication Conference (UEMCON) (pp. 1-6). IEEE.

Elkind, D. (1996). Young children and technology: A cautionary note. Young Children, 51(6), 22-23.

Euclid, p-ISSN 2355-1712, e-ISSN 2541-4453, Vol. 7, No. 2, pp. 77- 147

CLembaga Penelitian Universitas Swadaya Gunung Jati (UGJ), Cirebon. 
Ferreira, C. M., \& Serpa, S. (2018). Society 5.0 and Social Development. Management and Organizational Studies (5), 26-31.

Fujii, T., Guo, T., \& Kamoshida, A. (2018). A Consideration of Service Strategy of Japanese Electric Manufacturers to Realize Super Smart Society (SOCIETY 5.0). In International Conference on Knowledge Management in Organizations (pp. 634-645). Springer.

Fukuda, K. (2019). Science, technology and innovation ecosystem transformation toward society 5.0. International Journal of Production Economics, 107460.

Fukuyama, M. (2018). Society 5.0: Aiming for a new human-centered society. Japan Spotlight, 1, 47-50.

Gadanidis, G. (2017). Artificial intelligence, computational thinking, and mathematics education. The International Journal of Information and Learning Technology.

Genesereth, M. R., \& Nilsson, N. J. (2012). Logical foundations of artificial intelligence. Morgan Kaufmann.

Gladden, M. E. (2019). Who will be the members of Society 5.0? Towards an anthropology of technologically posthumanized future societies. Social Sciences, 8(5), 148.

Grover, S., \& Pea, R. (2018). Computational Thinking: A competency whose time has come. Computer Science Education: Perspectives on Teaching and Learning in School, 19.

Hart, L. C., Smith, S. Z., Swars, S. L., \& Smith, M. E. (2009). An examination of research methods in mathematics education (1995-2005). Journal of Mixed Methods Research, 3(1), 26-41.

Heliany, I. (2019). Wonderful Digital Tourism Indonesia Dan Peran Revolusi Industri Dalam Menghadapi Era Ekonomi Digital 5.0. Destinesia: Jurnal Hospitaliti Dan Pariwisata, 1(1), 21-35.

Kale, U., Akcaoglu, M., Cullen, T., Goh, D., Devine, L., Calvert, N., \& Grise, K. (2018). Computational What? Relating Computational Thinking to Teaching. TechTrends, 62(6), 574-584.

Keengwe, J., \& Onchwari, G. (2009). Technology and early childhood education: A technology integration professional development model for practicing teachers. Early Childhood Education Journal, 37(3), 209.

Khosla, R., Damiani, E., \& Grosky, W. (2003). Why Human-Centered eBusiness? In Human-Centered e-Business (pp. 1-12). Springer.

Lee, S.-H., \& Lee, D.-W. (2016). Actual cases for smart fusion industry based on internet of thing. Journal of the Korea Convergence Society, 7(2), 1-6.

Liu, J., \& Wang, L. (2010). Computational thinking in discrete mathematics. In 2010 Second International Workshop on Education Technology and Computer Science (pp. 413-416). IEEE. 
Luger, G. F. (2005). Artificial intelligence: structures and strategies for complex problem solving. Pearson education.

Mumtaha, H. A., \& Khoiri, H. A. (2019). Analisis Dampak Perkembangan Revolusi Industri 4.0 dan Society 5.0 Pada Perilaku Masyarakat Ekonomi (E-Commerce). Jurnal Pilar Teknologi: Jurnal Ilmiah Ilmu Ilmu Teknik, 4(2).

Nilsson, N. J. (2014). Principles of artificial intelligence. Morgan Kaufmann.

Orton, K., Weintrop, D., Beheshti, E., Horn, M., Jona, K., \& Wilensky, U. (2016). Bringing computational thinking into high school mathematics and science classrooms. Singapore: International Society of the Learning Sciences.

Pangkey, F. M., Furkan, L. M., \& Herman, L. E. (2019). Pengaruh Artificial Intelligence dan Digital Marketing terhadap Minat Beli Konsumen. Jurnal Magister Manajemen Unram Vol, 8(3).

Román-González, M., Pérez-González, J.-C., \& Jiménez-Fernández, C. (2017). Which cognitive abilities underlie computational thinking? Criterion validity of the Computational Thinking Test. Computers in Human Behavior, 72, 678-691.

Russell, S. J., \& Norvig, P. (2016). Artificial intelligence: a modern approach. Malaysia; Pearson Education Limited,.

Salgues, B. (2018). Society 5.0: industry of the future, technologies, methods and tools. John Wiley \& Sons.

Sediyono, E. (2019). Teknologi Humanis di Era Digital. In Prosiding Seminar Nasional Teknologi Informasi dan Komunikasi (SENATIK) (Vol. 2, pp. 1-6).

Sengupta, P., Kinnebrew, J. S., Basu, S., Biswas, G., \& Clark, D. (2013). Integrating computational thinking with $\mathrm{K}-12$ science education using agent-based computation: A theoretical framework. Education and Information Technologies, 18(2), 351-380.

Shiroishi, Y., Uchiyama, K., \& Suzuki, N. (2018). Society 5.0: For human security and well-being. Computer, 51(7), 91-95.

Sung, W., Ahn, J., \& Black, J. B. (2017). Introducing computational thinking to young learners: Practicing computational perspectives through embodiment in mathematics education. Technology, Knowledge and Learning, 22(3), 443-463.

Sysło, M. M., \& Kwiatkowska, A. B. (2014). Learning mathematics supported by computational thinking. Constructionism and Creativity, 258-268.

Tabesh, Y. (2017). Computational thinking: A 21st century skill. Olympiads in Informatics, 11, 65-70.

Tanwar, S., Patel, P., Patel, K., Tyagi, S., Kumar, N., \& Obaidat, M. S. (2017). An advanced internet of thing based security alert system for smart home. In 2017 International Conference on Computer, Information and Telecommunication Systems (CITS) (pp. 25-29). IEEE.

Euclid, p-ISSN 2355-1712, e-ISSN 2541-4453, Vol. 7, No. 2, pp. 77- 147

CLembaga Penelitian Universitas Swadaya Gunung Jati (UGJ), Cirebon. 
Tjandrawinata, R. R. (2016). Industri 4.0: Revolusi industri abad ini dan pengaruhnya pada bidang kesehatan dan bioteknologi. Jurnal Medicinus, 29(1), 31-39.

Voskoglou, M. G., \& Buckley, S. (2012). Problem solving and computational thinking in a learning environment. arXiv Preprint arXiv:1212.0750.

Wang, F., Kinzie, M. B., McGuire, P., \& Pan, E. (2010). Applying technology to inquiry-based learning in early childhood education. Early Childhood Education Journal, 37(5), 381-389.

Weintrop, D., Beheshti, E., Horn, M., Orton, K., Jona, K., Trouille, L., \& Wilensky, U. (2016). Defining computational thinking for mathematics and science classrooms. Journal of Science Education and Technology, 25(1), 127-147.

Wing, J. (2011). Research notebook: Computational thinking-What and why. The Link Magazine, 6.

Wing, J. M. (2006). Computational thinking. Communications of the ACM, 49(3), 33-35.

Wing, J. M. (2008). Computational thinking and thinking about computing. Philosophical Transactions of the Royal Society A: Mathematical, Physical and Engineering Sciences, 366(1881), 3717-3725.

Wing, J. M. (2014). Computational thinking benefits society. 40th Anniversary Blog of Social Issues in Computing, 2014.

Yadav, A., Zhou, N., Mayfield, C., Hambrusch, S., \& Korb, J. T. (2011). Introducing computational thinking in education courses. In Proceedings of the 42nd ACM technical symposium on Computer science education (pp. 465-470).

Yang, H., Mouza, C., \& Pan, Y.-C. (2018). Examining pre-service teacher knowledge trajectories of computational thinking through a redesigned educational technology course. International Society of the Learning Sciences, Inc.[ISLS].

Zhang, C., \& Green, R. (2015). Communication security in internet of thing: preventive measure and avoid DDoS attack over IoT network. In Proceedings of the 18th Symposium on Communications E Networking (pp. 8$15)$. 